\title{
The role of ingestional delay in taste-mediated environmental potentiation
}

\author{
MICHAEL R. BEST \\ Southern Methodist University, Dallas, Texas \\ JOHN D. BATSON \\ Furman University, Greenville, South Carolina \\ and \\ MARK T. BOWMAN \\ Southern Methodist University, Dallas, Texas
}

\begin{abstract}
We investigated sources of interference with taste-mediated environmental potentiation in Holtzman rats. Confinement in a novel environmental context for $15 \mathrm{~min}$ prior to saccharin ingestion prevented the development of enhanced lithium chloride-reinforced aversions to the environment. These results implicate the contribution of stimulus delay in the disruption of potentiation. They are discussed in terms of both special- and general-process conceptions of conditioning.
\end{abstract}

Although toxicosis readily supports the conditioning of taste cues, it is considerably less capable of conditioning distal cues that activate the olfactory system. Some reports have demonstrated, however, that conditioning of olfactory cues may be enhanced if they are presented in compound with a taste cue during conditioning trials (e.g., Bouton, Dunlap, \& Swartzentruber, 1987; Durlach \& Rescorla, 1980; Palmerino, Rusiniak, \& Garcia, 1980; Rusiniak, Hankins, Garcia, \& Brett, 1979). This outcome is generally called potentiation, because the taste facilitates the conditioning of an otherwise less salient olfactory cue. Similar taste-mediated potentiation effects have been observed in toxiphobia procedures with rats using environmental stimuli (Best, Brown, \& Sowell, 1984), auditory stimuli (Ellins \& von Kluge, 1987), the visual properties of food (Galef \& Osborne, 1978), and other tastes (Bouton et al., 1987; Davis, Best, \& Grover, 1988). Potentiation has been of interest for many reasons, not the least of which is its apparent conflict with a Pavlovian phenomenon known as overshadowing. Pavlov (1927) and others (e.g., Kamin, 1969; Mackintosh, 1971, 1975; Pearce \& Hall, 1980; Rescorla \& Wagner, 1972; Revusky, 1971; Wagner, 1976, 1981) have demonstrated that when two elements of a compound conditioned stimulus are followed by an unconditioned stimulus, conditioning of the less salient element is attenuated.

This work was supported by National Science Foundation Grant BNS8809508 to Michael R. Best and National Institute of Mental Health Grant MH40976 to John D. Batson. We thank Neil Fulbright, Hemlata Patel, and Travis White for their technical assistance in conducting this experiment. Some of the data from this experiment were presented at the 28th Annual Meeting of the Psychonomic Society, Seattle, WA. Correspondence may be addressed to Michael R. Best, Psychology Department, Southern Methodist University, Dallas, TX 75275.
Because potentiation seems to represent an exception to traditional conditioning outcomes (viz., overshadowing), much research has been devoted to an examination of the specific associative processes that govern the phenomenon. One factor that should be important in the development of taste-mediated potentiation is the temporal arrangement of the components of the compound stimulus. Using a delay procedure, Coburn, Garcia, Kiefer, and Rusiniak (1984) allowed rats to drink water in the presence of an environmental odor for $5 \mathrm{~min}$. Either 2 or 5 min after removal of the odor stimulus, the rats were then exposed for $2 \mathrm{~min}$ to a novel taste dissolved in water and intubated with an isotonic solution of lithium chloride. Odor aversions in these groups were then compared with those in rats that drank the taste in the presence of the odor during conditioning or drank water only in the presence of the odor during conditioning. No odor aversions were noted in the animals that received odor alone during conditioning or in those that received odor $5 \mathrm{~min}$ prior to drinking the taste, and weak odor aversions were observed in the groups that received odor $2 \mathrm{~min}$ prior to taste exposure. In contrast, strong aversions were seen in the animals that received odor in the presence of taste during conditioning. These results indicate that temporal overlap of the odor and taste is an important condition in the production of odor potentiation.

The present experiment extended the temporal analysis offered by Coburn et al. (1984), using an environmental potentiation procedure. Prior to lithium injections, all animals in the key experimental groups drank a taste while confined in a novel compartment. For all animals, the intervals between saccharin onset, saccharin offset, and the toxin injection were held constant. The groups differed only in the amount of time they spent in the experimental environment prior to receiving saccharin. One group 
received saccharin immediately upon placement in the environment. For this group, the onset properties of the taste and the environment coincided. The animals in the second group were placed in the experimental environment $15 \mathrm{~min}$ prior to the introduction of the saccharin solution. For this group, the onset of contextual stimuli preceded taste stimulation by $15 \mathrm{~min}$. This manipulation would be expected to interfere with the association between the environment and the taste. If compound associations are important to the production of potentiation, the overall aversiveness of the environmental stimuli should therefore be reduced.

\section{METHOD}

\section{Subjects and Apparatus}

The subjects were 39 male adult Holtzman rats, born and raised in the animal colony at Southern Methodist University. From birth and during the experiment, they were maintained on a $12-\mathrm{h}$-light/12-h-dark schedule, housed individually in standard Wahmann wire-mesh cages, and given access to food (Wayne Lab Blox) ad lib. All fluid was delivered via 50 -ml polypropylene centrifuge tubes equipped with rubber stoppers and metal spouts. Intakes were measured to the nearest $0.1 \mathrm{~g}$ using an Ohaus electronic balance.

The experimental environments were polypropylene mouse-breeding cages situated side by side on a three-tiered stainless steel rack residing in an adjacent room. Fluids available during the experiment included a $0.15 \%$ saccharin solution (w/v, mixed with room-temperature tap water) and room-temperature tap water. Injections were administered intraperitoneally using an isotonic solution of lithium chloride $(0.15 \mathrm{M})$ at a dose of $1.2 \%$ of body weight.

\section{Procedure}

Prior to the initiation of the experimental procedures, all animals were organized into four groups ( $n=10$ per group) equilibrated as closely as possible by weight and fluid intake. Each animal was initially familiarized with a $0.9 \%$ saline solution, receiving this fluid for 20 min each day for 12 consecutive days. All animals then drank water for $20 \mathrm{~min}$ daily on each of the 9 days prior to conditioning. On the day prior to conditioning, 1 animal was removed from the experiment because of respiratory illness.

Conditioning took place on 4 consecutive days following saline preexposure. Animals in the SAC/BOX $(5)$ group $(n=9)$ were placed in the experimental boxes for $5 \mathrm{~min}$ and received $20 \mathrm{ml}$ of $0.15 \%$ saccharin solution for the duration of this 5-min session. Animals in the $\mathrm{H}_{2} \mathrm{O} / \mathrm{BOX}(5)$ group $(n=10)$ were also placed in the environmental chambers for $5 \mathrm{~min}$. Instead of saccharin, they had access to $20 \mathrm{ml}$ of water during this 5-min period. Animals in the SAC/BOX(20) group $(n=10)$ were placed in the environment for $20 \mathrm{~min}$, the last $5 \mathrm{~min}$ of which they had access to $20 \mathrm{ml}$ of saccharin. The animals in the $\mathrm{H}_{2} \mathrm{O} / \mathrm{BOX}(20)$ group $(n=10)$ were also placed in the experimental environments for $20 \mathrm{~min}$, receiving water the last $5 \mathrm{~min}$ of this period. All animals were then removed from the environments, injected with lithium chloride and returned to their home cages. Four hours after each conditioning session, all animals received access to $40 \mathrm{ml}$ of saline solution for $20 \mathrm{~min}$ in their home cages. For the next 10 days, all animals received $40 \mathrm{ml}$ of saline solution for $20 \mathrm{~min}$ in their home cages.

The first of three environmental tests was conducted $24 \mathrm{~h}$ after the last saline-maintenance session. For this test, all animals were placed in the experimental environments for $20 \mathrm{~min}$ with continuous access to $40 \mathrm{ml}$ of saline solution. The animals were then returned to their home cages and intakes were recorded. To equilibrate intakes on the day of testing, each animal was then given the remainder of its $40 \mathrm{ml}$ of saline in the home cage. Second and third tests, identical to the first, were administered 24 and $48 \mathrm{~h}$, respectively, after the initial test session.

Twenty-four hours after the final environmental test, all animals received saccharin in their home cages for $20 \mathrm{~min}$. This test was used to evaluate the saccharin aversions in each group. This saccharin ex- posure was followed by a 20 -min saline-maintenance session for all animals. Identical test sessions were conducted on the following 3 days.

Statistical evaluations of the between-group data were performed using the Mann-Whitney $U$ test, two-tailed $(p<.05)$.

\section{RESULTS}

\section{Water Familiarization}

Water intake on the day prior to conditioning did not differ between any of the four groups (lowest $U=27$, $p>.10$ ). The means ranged from 20.7 to $24.2 \mathrm{ml}$ on this 20 -min encounter.

\section{Conditioning}

Intakes decreased substantially across trials for the two groups drinking saccharin during the 5-min conditioning exposure. The mean intake for Group SAC/BOX(5) on Conditioning Day 1 was $7.1 \mathrm{ml}$, and on Day 4 it was $0.1 \mathrm{ml}$. Parallel mean intakes for Group SAC/BOX(20) were 8.9 and $0.3 \mathrm{ml}$. A similar intake pattern was also observed in the $\mathrm{H}_{2} \mathrm{O} / \mathrm{BOX}$ groups across conditioning. Mean intakes for the $\mathrm{H}_{2} \mathrm{O} / \mathrm{BOX}(5)$ group were $5.63 \mathrm{ml}$ on Trial 1 and $0.28 \mathrm{ml}$ on Trial 4. Parallel intakes were 11.3 and $1.0 \mathrm{ml}$ for the $\mathrm{H}_{2} \mathrm{O} / \mathrm{BOX}(20)$ group. These intake differences between the $\mathrm{H}_{2} \mathrm{O} / \mathrm{BOX}$ groups were significant on Day $1(U=7, p<.05)$, as were those between both $\mathrm{H}_{2} \mathrm{O} / \mathrm{BOX}$ groups and the two SAC/BOX groups on Day 2 (highest $U=23, p=.05$ ).

Saline intakes during the 20-min afternoon maintenance periods were not significantly different for any of the groups on any of the four conditioning trials (lowest $U=$ $24, p>.05$; means ranged from 21.3 to $35.0 \mathrm{ml}$ ). Moreover, there were no significant differences in saline consumption for any of the groups on the last day prior to the environmental test (lowest $U=43.5, p>.10$; means ranged from 34.5 to $36.5 \mathrm{ml}$ ).

\section{Environmental Test}

Figure 1 displays the mean intakes on the 20-min saline test in the experimental environment for all four groups on Test Day 1. Group SAC/BOX(5) consumed significantly less saline on this test than any of the other three groups (highest $U=18, p<.05$ ). None of the other groups differed significantly on this day (lowest $U=$ 30.5). This pattern was evident on Test Day 2 as well. The animals in Group SAC/BOX(5) drank a mean of $11.5 \mathrm{ml}$ of saline on this test, and the means in the other groups ranged from 21.7 to $23.6 \mathrm{ml}$. The intakes in the SAC/BOX(5) group were significantly less than those in all the other groups on Test Day 2 (lowest $U=18, p<$ $.05)$. By Test Day 3 , all groups were drinking comparably (means ranged from 15.8 to $21.6 \mathrm{ml}$; lowest $U=$ 29.5, $p>.10)$.

\section{Taste Tests}

Substantial and significant aversions were established in both SAC/BOX groups on the 20-min test in the home cages. Mean intakes on Test Day 1 were $4.7 \mathrm{ml}$ for Group $\mathrm{SAC} / \mathrm{BOX}(5)$ and $2.22 \mathrm{ml}$ for Group SAC/BOX(20); 


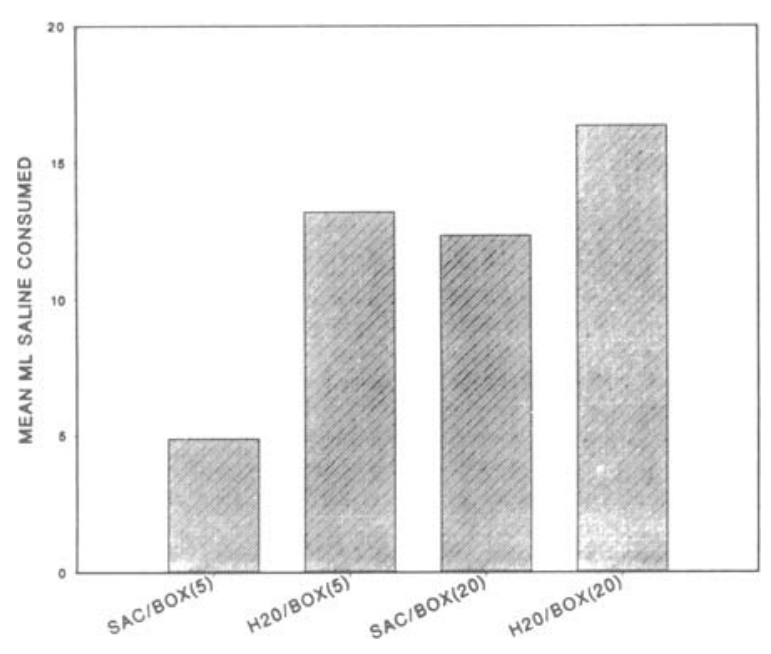

Figure 1. Mean saline intake for each of the four groups on the first environmental test. Group SAC/BOX(5) drank 0.15\% saccharin for 5 min on each of four 5-min confinements in the experimental environment. Each confinement was followed by $0.15 \mathrm{M}, 1.2 \%$ of b.w. injections of lithium chloride. Group $\mathrm{H}_{2} \mathrm{O} / \mathrm{BOX}(5)$ drank water during otherwise identical conditioning trials. Group SAC/ BOX (20) drank saccharin the last 5 min on each of four 20-min confinements in the experimental environment, followed by lithium chloride injections. Group $\mathrm{H}_{2} \mathrm{O} / \mathrm{BOX}(20)$ drank water on otherwise identical conditioning trials.

mean intakes on the same test day for the parallel $\mathrm{H}_{2} \mathrm{O}$ / BOX groups were 16.8 and $17.4 \mathrm{ml}$ (highest $U=5$, $p<.05)$. Of particular interest were the differences between the SAC/BOX(5) and SAC/BOX(20) groups on the saccharin tests. Saccharin consumption on the four tests was significantly higher in Group SAC/BOX(5) than in Group SAC/BOX(20) [combined mean for Group SAC/ $\operatorname{BOX}(20)=6.0 \mathrm{ml}$, combined mean for Group $\mathrm{SAC} / \mathrm{BOX}(5)=13.2 \mathrm{ml} ; U=17, p<.05]$.

\section{DISCUSSION}

The outcome of primary importance in this experiment was the failure to observe taste-mediated environmental potentiation in the SAC/BOX(20) group on the initial environmental tests. Whereas the animals in Group SAC/BOX(5) consumed significantly less saline on these 20-min ingestional tests than their comparison control group [Group $\mathrm{H}_{2} \mathrm{O} / \mathrm{BOX}(5)$ ], the animals in Group SAC/BOX(20) drank significantly more on this test than those in the SAC/BOX(5) group, and drank similar amounts to those in both the $\mathrm{H}_{2} \mathrm{O} / \mathrm{BOX}(20)$ and the $\mathrm{H}_{2} \mathrm{O} / \mathrm{BOX}(5)$ groups. This difference could not have been due to stronger saccharin aversions learned in the SAC/BOX(5) group since, if anything, the animals in this group actually learned less of a saccharin aversion than did those in the SAC/BOX(20) group. These results, then, point to the critical role the environmental cues played in the disruption of potentiation in the SAC/BOX(20) group.

The manner in which the environmental manipulation in Group SAC/ BOX(20) disrupted potentiation is worth consideration. In this group, each animal was placed in the environment $15 \mathrm{~min}$ prior to receiving saccharin. This manipulation introduced a delay between the onset of the environmental stimuli and the onset of the potentiating stimulus. Such exposure could have temporarily habituated the environmental stimuli, thereby reducing their salience.

The difference in saccharin aversions between the SAC/BOX(5) and SAC/BOX(20) groups also deserves some comment. It is likely that the
SAC/BOX(20) animals drank significantly less saccharin than the SAC/ BOX(5) animals on the tests because of differential overshadowing of the saccharin by the environmental cues in the two groups. For the animals in the SAC/BOX(5) group, the environmental cues were novel at the time that taste was introduced. This should increase the likelihood of taste overshadowing. In contrast, the animals in the SAC/ BOX(20) group drank saccharin in a compartment to which they had already received $15 \mathrm{~min}$ of familiarization. This manipulation would be expected transiently to reduce the salience of the environmental stimuli, thereby rendering the taste relatively more associable with toxicosis. This outcome is particularly interesting in light of the enhanced aversion noted in the SAC/BOX(5) group to the environmental cues. The animals in this group evidenced potentiated aversions to stimuli that, in turn, were exerting a disruptive effect on the conditioning of a concomitant taste.

\section{Conclusion}

The experiment reported here was conducted to clarify further the mechanisms underlying taste-mediated environmental potentiation. Most of the potentiation data in the literature have been interpreted within one of two theoretical frameworks. One, initially proposed by Garcia and his colleagues (Garcia, 1988; Palmerino et al., 1980), emphasizes the special status of potentiation within the feeding system. In support of this proposal, virtually all instances of stimulus potentiation occur in toxicosis procedures using taste as the mediating factor. The second framework, originally offered by Rescorla and his colleagues (Durlach \& Rescorla, 1980; Rescorla \& Durlach, 1981), focuses on the general associative structures underlying taste-mediated potentiation. This perspective emphasizes cross-paradigmatic processes. The primary evidence in this regard has been the role of associative compounding in the production of potentiation.

The necessity of associations between a taste and other feeding-related stimuli in taste-mediated environmental potentiation can be inferred from the results of the present experiment. Confinement of rats in the experimental environment for $15 \mathrm{~min}$ prior to introducing the taste solution significantly interfered with the ability of these environmental stimuli to become the object of potentiation. If the association between environmental stimuli and taste is a key ingredient in producing potentiation, a delay between the onset of these stimuli would be expected to interfere with this association. In contrast, simultaneous onset of the stimuli should create the optimal conditions for this association. Consistent with this paradigm, rats offered the taste immediately upon confinement in the experimental compartment evidenced the strongest aversion to the environmental cues.

On balance, though, it is important to recognize that taste-mediated potentiation has thus far been limited to toxiphobia procedures. In addition, although an aversive taste is capable of enhancing conditioning to other stimuli, these other cues significantly overshadow the development of a taste aversion (e.g., Best \& Meachum, 1986; Westbrook, Homewood, Horn, \& Clarke, 1983). This associative asymmetry is perhaps not surprising because, for the feeding rat, tastes, smells, sights, and sounds all play an integral role in the relevant appetitive and consummatory behavior. Unlike conditioning preparations in which the stimuli tend to be easily differentiated, the natural relationship of the events in ingestional conditioning may make these procedures particularly useful in isolating the rules of associative assimilation.

\section{REFERENCES}

Best, M. R., Brown, E. R., \& Sowell, M. L. (1984). Taste-mediated potentiation of noningestional stimuli in rats. Learning \& Motivation, 15, 244-258.

Best, M. R., \& Meachum, C. L. (1986). The effects of stimulus preexposure on taste-mediated environmental conditioning: Potentiation and overshadowing. Animal Learning \& Behavior, 14, 1-5.

Bouton, M. E., Dunlap, C. N., \& Swartzentruber, D. (1987). Potentiation of taste by another taste during compound aversion learning. Animal Learning \& Behavior, 15, 433-438.

Coburn, K. L., Garcia, J., Kiefer, S. W., \& Rusiniak, K. W. (1984). Taste potentiation of poisoned odor by temporal contiguity. Behavioral Neuroscience, 98, 313-319. 
Davis, S. F., Best, M. R., \& Grover, C. A. (1988). Toxicosis-mediated potentiation in a taste/taste compound: Evidence for within-compound associations. Learning \& Motivation, 19, 183-205.

Durlach, P. J., \& Rescorla, R. A. (1980). Potentiation rather than overshadowing in flavor-aversion learning: An analysis in terms of within-compound associations. Journal of Experimental Psychology: Animal Behavior Processes, 6, 175-187.

Ellins, S. R., \& von Kluge, S. (1987). Preexposure and extinction effects of lithium chloride induced taste-potentiated aversions for spatially contiguous auditory food cues in rats. Behavioral Neuroscience, 101, 164-169.

Galef, B. G., \& OsBorne, B. (1978). Novel taste facilitation of the association of visual cues with toxicosis in rats. Journal of Comparative \& Physiological Psychology, 92, 907-916.

GARCIA, J. (1988). Food for Tolman: Cognition and cathexis in concert. In T. Archer \& L. G. Nilsson (Eds.), Aversion, avoidance, and anxiety: Perspectives on aversively motivated behavior (pp. 45-85). Hillsdale, NJ: Erlbaum.

Kamin, L. J. (1969). Predictability, surprise, attention, and conditioning. In B. A. Campbell \& R. M. Church (Eds.), Punishment and aversive behavior (pp. 279-296). New York: Appleton-Century-Crofts.

Mackintosh, N. J. (1971). An analysis of overshadowing and blocking. Quarterly Journal of Experimental Psychology, 23, 118-125.

Mackintosh, N. J. (1975). A theory of attention: Variations in the associability of stimuli with reinforcement. Psychological Review, 82, 276-298.

Palmerino, C. C., Rusiniak, K. W., \& Garcia, J. (1980). Flavorillness aversions: The peculiar roles of odor and taste in memory for poison. Science, 208, 753-755.

Pavlov, I. P. (1927). Conditioned reflexes (G. V. Anrep, Trans.). London: Oxford University Press.

Pearce, J. M., \& Hall, G. (1980). A model for Pavlovian learning:
Variations in the effectiveness of conditioned but not of unconditioned stimuli. Psychological Review, 87, 356-367.

Rescorla, R. A., \& Durlach, P. J. (1981). Within-event learning in Pavlovian conditioning. In N. S. Spear \& R. R. Miller (Eds.), Information processing in animals: Memory mechanisms (pp. 81-111). Hillsdale, NJ: Erlbaum.

Rescorla, R. A., \& Wagner, A. R. (1972). A theory of Pavlovian conditioning: Variations in the associability of stimuli with reinforcement. In A. Black \& W. F. Prokasy (Eds.), Classical conditioning: II. Current theory and research (pp. 64-99). New York: AppletonCentury-Crofts.

REVUSKY, S. (1971). The role of interference in association over a delay. In W. K. Honig \& Y. P. R. James (Eds.), Animal memory (pp. 155-213). New York: Academic Press.

Rusiniak, K. W., Hankins, W. G., Garcia, J., \& Brett, L. P. (1979). Flavor-illness aversions: Potentiation of odor by taste in rats. $\mathrm{Be}$ havioral \& Neural Biology, 5, 1-17.

Wagner, A. R. (1976). Priming in STM: An information-processing mechanism for self-generated or retrieval-generated depression in performance. In T. J. Tighe \& R. N. Leaton (Eds.), Habituation: Perspectives from child development, animal behavior, and neurophysiology (pp. 95-128). Hillsdale, NJ: Erlbaum.

W AGNER, A. R. (1981). SOP: A model of automatic processing in animal behavior. In N. Spear \& R. R. Miller (Eds.), Information processing in animals: Memory mechanisms (pp. 5-47). Hillsdale, NJ: Erlbaum.

Westbrook, R. F., Homewood, J., Horn, K., \& Clarke, J. C. (1983). Flavor-odor compound conditioning: Odor potentiation and flavor attenuation. Quarterly Journal of Experimental Psychology, 35, 13-33.

(Manuscript received October 5, 1989.) 